\title{
ELECTRON MICROSCOPICAL ANALYSIS OF MEIOTIC CHROMOSOMES FROM HUMAN SPERMATOCYTES DURING AND AFTER TREATMENT WITH STEROID HORMONES
}

\author{
by \\ JØRGEN G. BERTHELSEN ${ }^{1+2)}$, MARIE FØGH ${ }^{3)}$ and NIELS E. SKAKKEBÆK ${ }^{\prime \prime}$ \\ 1)Laboratory of Reproductive Biology, University Department of Obstetrics and Gynaecology YA, \\ Rigshospitalet, Blegdamsvej 9, DK-2100 Copenhagen Ø \\ 2)Department of Physiology, Carlsberg Laboratory, Gamle Carlsberg Vej 10, DK-2500 Copenhagen Valby \\ 3)Department of Gynaecology and Obstetrics, Herlev Hospital, University of Copenhagen, DK-2730 Herlev
}

Keywords: Synaptonemal complex, pachytene, recombination nodules, cyproterone acetate, testosterone, d-norgestrel

The effect of steroid hormones on the ultrastructure of meiosis in the human male was analyzed by three dimensional reconstruction of 460 chromosomes from 7 early pachytene, 2 mid pachytene and 1 late pachytene spermatocyte nuclei. The testicular biopsy was obtained from a volunteer who had been treated with d-norgestrel $500 \mathrm{mcg}$ per day orally and testosterone enanthate $200 \mathrm{mg}$ every 4 weeks intramuscularly for 8 months and who was still under treatment. The volunteer had 17 months previously been treated with cyproterone acetate $5 \mathrm{mg}$ per day orally for 6 months.

The analysis of the synaptonemal complex, the number and distribution of recombination nodules and the general morphology of the bivalents did not reveal any damage by the hormonal treatment. In addition to the morphological features of human pachytene spermatocytes described in literature, bridgelike structures uniting the lateral components of the synaptonemal complex was found.

\section{INTRODUCTION}

Several steroid hormones are presently being studied as prospective male contraceptives ( 7 , 13). These studies are primarily concerned with the short and long term effects on spermatogenesis as revealed by semen analysis and on metabolism and psychological reactions. However, it is also important to investigate the effect on chromosome pairing and crossing over during meiosis as well as the incidence of chromosomal abnormalities during and after the treatment.

Light microscopical examination of testicular biopsies gives information on testicular histology and the quality of spermatogenesis $(4,17,19)$ while light microscopical examination of meiotic 
chromosomes yields information about the number of bivalents, their gross structure and the frequency and distribution of chiasmata (11, 18). More detailed information on chromosome pairing and crossing over has been obtained by three dimensional reconstruction of the synaptonemal complex from electron micrographs (8, 20, 21). Detailed investigations employing this technique based on a total of 65 completely reconstructed nuclei from normal human spermatocytes are now available $(8,15,16)$ and is the reference material for the present investigation.

\section{MATERIALS AND METHODS}

\subsection{Patient}

The testicular biopsy was obtained from a 27 years old volunteer participating in an investigation of the effect of different steroid hormones on spermatogenesis $(5,6)$.

The volunteer had been treated with a daily dose of $5 \mathrm{mg}$ cyproterone acetate orally for 6 months. During this treatment semen samples showed a decrease of the concentration of spermatozoa from an average of $175 \times 10^{6} / \mathrm{ml}$ to an average of $65 \times 10^{6} / \mathrm{ml}$. During the following 9 months without treatment the concentration of spermatozoa increased to an average of $220 \times 10^{6} / \mathrm{ml}$. Treatment was then instituted with a daily dose of $500 \mathrm{mcg}$ dnorgestrel orally and testosterone enanthate 200 mg every 4 weeks intramuscularly. During this treatment semen samples showed a decrease of the concentration of the spermatozoa to an average of $70 \times 10^{6} / \mathrm{ml}$. After 8 months' treatment and while the volunteer was still receiving the drugs, the testicular biopsy was obtained.

\subsection{Light microscopy}

The tissue specimen for light microscopy was fixed in Cleland's fixative, dehydrated in alcohol, embedded in paraplast and sectioned serially. The $4 \mu \mathrm{m}$ sections were stained with ironhaematoxylin and eosin.

Qantification of the seminiferous epithelium (19) was performed by counting the number of Sertoli cells and of spermatogenic cells in 30 cross-sections of seminiferous tubule and calculating the ratio of the different germinal cells to the Sertoli cells (Table I).

\subsection{Electron microscopy}

The tissue specimen for electron microscopy was cut in $1 \times 2 \times 2 \mathrm{~mm}$ pieces and immediately fixed in $4 \%$ glutar aldehyde (purification index $0.2(1))$ in $0.06 \mathrm{M}, \mathrm{pH} 7.2$ phosphate buffer for 3 hours at room temperature, rinsed twice in phosphate buffer, 5 times in distilled water and left overnight in distilled water a $4{ }^{\circ} \mathrm{C}$. The tissue was then stained in $2 \%$ aqueous uranyl acetate for 3 hours at $60^{\circ} \mathrm{C}$, dehydrated in alcohol, embedded in Spurr's low viscosity resin and polymerized at $70{ }^{\circ} \mathrm{C}$ overnight (15). Sections of $1 \mu \mathrm{m}$ were examined and when

Table I

Light microscopical quantification of the spermatogenic epithelium. The figures are the Sertoli cell ratios, i.e. the number of cells per Sertoli cell in $\mathbf{3 0}$ cross-sections of seminiferous tubule.

\begin{tabular}{|c|c|c|c|c|c|c|}
\hline & \multirow[t]{2}{*}{ Spermatogonia } & \multicolumn{3}{|c|}{ Spermatocytes } & \multicolumn{2}{|c|}{ Spermatids } \\
\hline & & PL & $\mathrm{L}$ & Z-P & $\mathrm{Sa}-\mathrm{Sb}$ & $\mathrm{Sc}-\mathrm{Sd}$ \\
\hline Volunteer & 2.15 & 0.02 & 0.10 & 1.12 & 1.80 & 0.90 \\
\hline \multicolumn{7}{|c|}{ Reference (19) } \\
\hline Mean & 1.17 & 0.25 & 0.22 & 1.96 & 3.05 & 2.14 \\
\hline Range & $1.05-2.83$ & $0.06-0.44$ & $0.08-0.38$ & $1.03-2.86$ & $1.59-4.87$ & $1.44-3.63$ \\
\hline
\end{tabular}

L: Leptotene, PL: Preleptotene, Sa-Sb: Early spermatids, Sc-Sd: Late spermatids, Z-P: Zygotene and pachytene. 
spermatocytes of the appropriate stage were encountered, 250-300 $0.08 \mu \mathrm{m}$ serial sections were cut on a Reichert Om U3 ultramicrotome equipped with a diamond knife. The sections were picked up from the trough with a single slot grid without formvar film and transferred to a single slot grid with formvar film with the aid of a micromanipulator. The sections were stained in $5 \%$ aqueous uranyl acetate for $1 / 2$ hour at 60 ${ }^{\circ} \mathrm{C}$ and in $5 \%$ lead citrate for $20 \mathrm{~min}$. at room temperature in an automatic staining apparatus.

The sections were examined in a Siemens Elmiscop 102 at a primary magnification of 4,000 times. The nucleus chosen for examination was identified in each of the sections and micrographed.Each pachytene nucleus appeared on 100-120 sections.

\subsection{Three dimensional reconstruction}

From each micrograph the pieces of synaptonemal complex were traced onto a transparent plastic sheet, tracings from 10 consecutive sections being drawn on the same sheet together with the appropriate section numbers. For each chromosome all segments from the different sheets were then transferred to a new plastic sheet (8).

The projected lengths of the chromosomes were measured with a Hewlett-Packard digitizer HP 9864A and the absolute lengths calculated with the aid of a Hewlett-Packard calculator HP 9825A $(8,15)$.

The autosomal chromosomes were classified according to length and centromere index (14). The diffuse heterochromatin and unpaired regions of the secondary constrictions on chromosomes 1, 9 and 16 and the nucleoli of the acrocentric chromosomes served as morphological markers of these chromosomes $(8,15)$. In this way it was usually possible to identify all chromosomes but nos. 4-8, 10, 13-15. These could, however, be assigned to Denver groups and numbered tentatively. An idiogram for each nucleus was automatically drawn by a HewlettPackard HP 9872A four colour plotter.

\subsection{Chromosome pairing and synaptonemal complex formation in untreated spermatocytes}

The aspects of meiosis relevant for the present investigation can be summarized as follows from the detailed analysis of the normal meiosis in human males presented by HoLM \& RASMUSSEN (8), RasmusSEN \& Holm (15) and Holm, RasmusSEN \& VON WeTTSTEIN (10). For a more general review on the synaptonemal complex the reader is referred to WeSTERGaARD \& VON WETTSTEIN (21).

During the leptotene stage of the meiotic prophase each chromosome organizes a lateral component which becomes attached to the nuclear envelope at both ends by the telomeres (e.g. Figure 3). All attachment sites are concentrated within a limited area of the nuclear envelope giving rise to the socalled chromosome bouquet (Figure 9). During the zygotene stage homologous chromosomes are paired as their lateral components are united by a central region thereby forming the synaptonemal complex (Figure 1). The lateral components have a diameter of $30-40 \mathrm{~nm}$, while the central region is 110 $120 \mathrm{~nm}$ broad. The pairing and synaptonemal complex formation is complete except for the secondary constrictions as the cell enters the early pachytene stage. The homologous segments of the $\mathrm{X}$ and $\mathrm{Y}$ chromosomes are usually paired with a synaptonemal complex at this stage while the differential segments remain unpaired (Figures 2 and 9). During mid pachytene the unpaired segments of the $\mathrm{X}$ and $\mathrm{Y}$ chromosomes become increasingly tortuous and appear discontinuous (Figure 6). In normal human late zygotene spermatocytes a number of bivalents and chromosomes are caught between the lateral components of partially paired bivalents while at early pachytene such interlockings are rare. According to RASMUSSEN \& HOLM ( 15 ) interlockings are resolved by breakage and reunion of the broken parts. From the first appearance of synaptonemal complexes at the beginning of zygotene electron dense nodules can be recognized in or at the central region of the synaptonemal complex. These so-called recombination nodules measure 30-150 $\mathrm{nm}$, are usually spherical or rod-shaped (Figures 3 and 4) and considered to participate in crossing over $(2,3)$. At mid and late pachytene the number of 

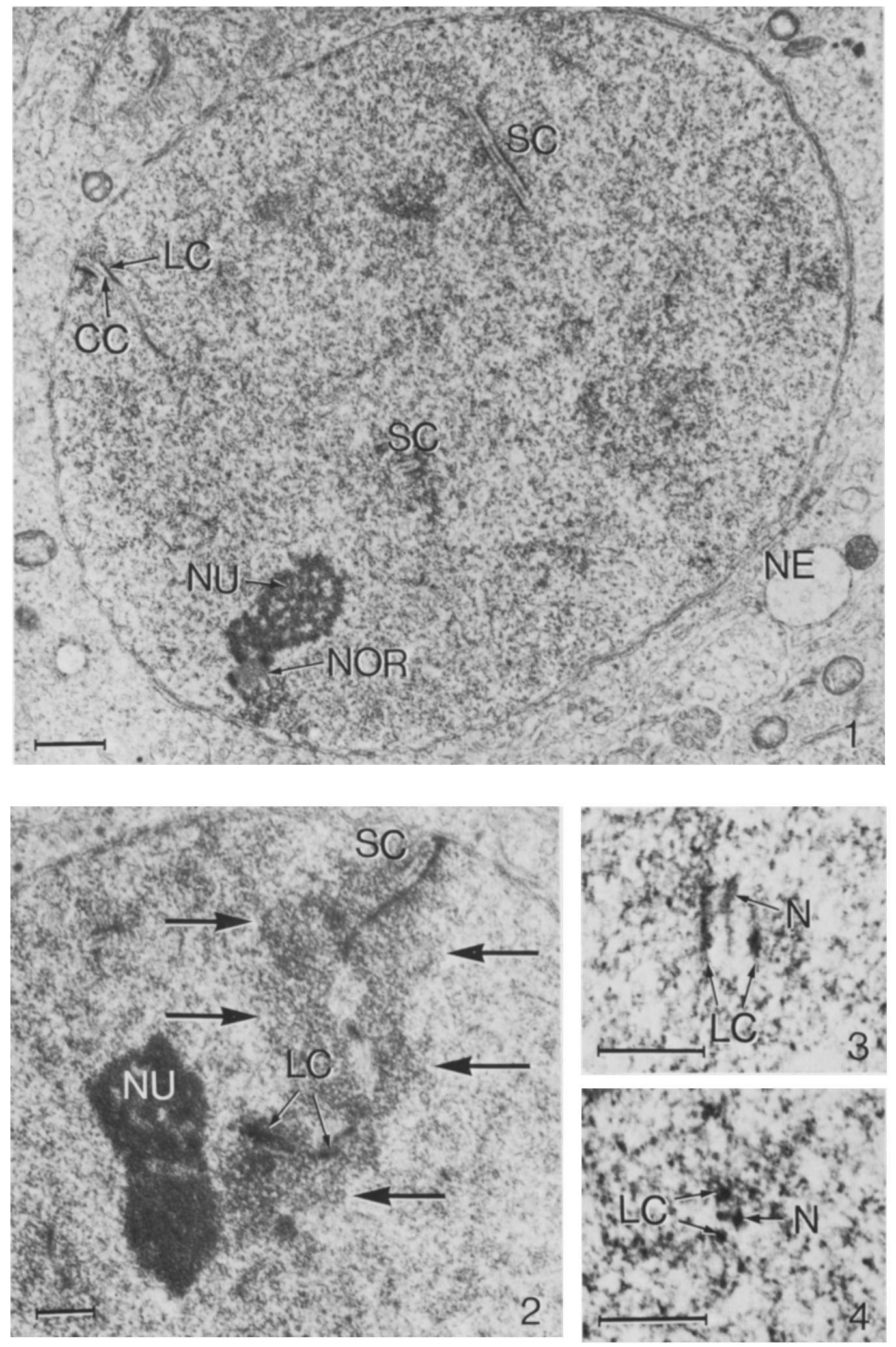

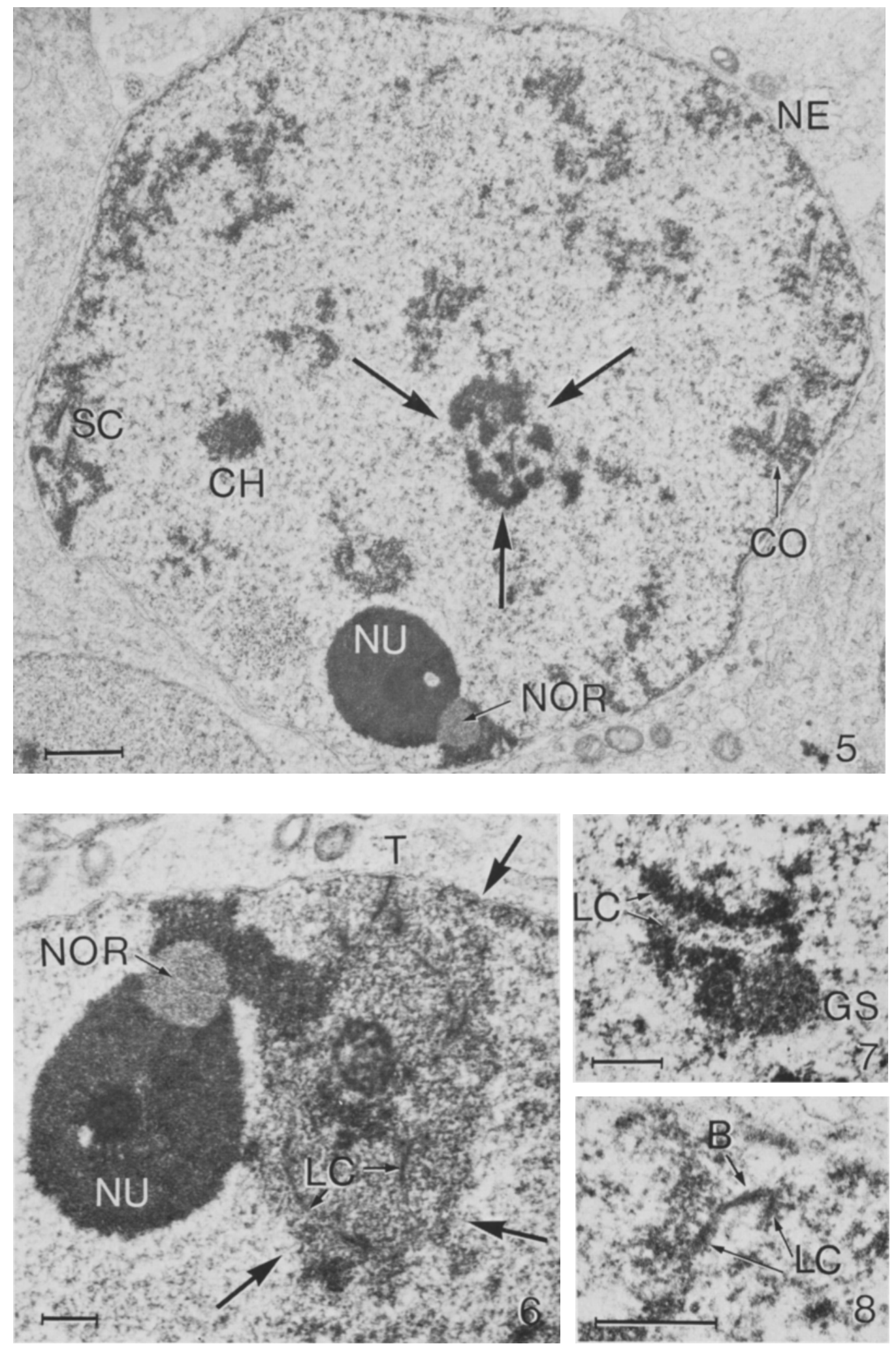
Figure 1. Survey micrograph of an early pachytene spermatocyte nucleus.

CC: Central component of the synaptonemal complex, LC: Lateral component of the synaptonemal complex, NE: Nuclear envelope, NOR: Nucleolus organizer region, NU: Nucleolus. SC: Synaptonemal complex. Bar: 1.0 $\mu \mathrm{m}$.

Figure 2. XY bivalent of an early pachytene spermatocyte nucleus.

LC: Lateral component of the differential segment of the X chromosome, NU: Nucleolus associated with the $\mathrm{XY}$ bivalent, SC: Synaptonemal complex between the homologous regions of the $\mathrm{X}$ and $\mathrm{Y}$ chromosomes. Arrows point to the $\mathrm{XY}$ bivalent. Bar: $0.5 \mu \mathrm{m}$.

Figure 3. Recombination nodule in an early pachytene spermatocyte nucleus.

LC: Lateral components of the synaptonemal complex, N: Recombination nodule, sectioned longitudinally. Bar: $0.5 \mu \mathrm{m}$.

Figure 4. Recombination nodule in an early pachytene spermatocyte nucleus.

LC: Lateral components of the synaptonemal complex, N: Recombination nodule in cross section. Bar: 0.5 $\mu \mathrm{m}$.

Figure 5. Survey micrograph of a mid pachytene spermatocyte nucleus.

$\mathrm{CH}$ : Centromeric heterochromatin, CO: Condensed chromatin, NE: Nuclear envelope, NOR: Nucleolus organizer region, NU: Nucleolus, SC: Synaptonemal complex. Arrows point to the diffuse heterochromatin of a secondary constriction. Bar: $1.0 \mu \mathrm{m}$.

Figure 6. XY bivalent of a mid pachytene spermatocyte nucleus.

Note the tortuous lateral components. The centromeric heterochromatin of one of the acrocentric bivalents is associated with the XY bivalent. LC: Lateral component. NOR: Nucleolus organizer region, NU: Nucleolus, T: Telomere. Arrows point to the XY bivalent. Bar: $0.5 \mu \mathrm{m}$.

Figure 7. Globular structure on bivalent 6 or 7 of a late pachytene spermatocyte nucleus.

GS: Globular structure. LC: Lateral components with condensed chromatin. Bar: $0.5 \mu \mathrm{m}$.

Figure 8. Synaptonemal complex with bridge-like structure between the two lateral components in a late pachytene spermatocyte nucleus.

B: Bridge-like structure, LC: Lateral components. Bar: $0.5 \mu \mathrm{m}$.

recombination nodules is reduced to $5-10$ per nucleus.

The recombination nodules are not distributed at random along the synaptonemal complexes as they are scarce on the short arms of the acrocentric chromosomes, at the secondary constrictions, in the centromeric heterochromatin and just outside the centromeres. The recombination nodules are relatively abundant distally on the synaptonemal complexes.

Stageing: $(8,15,21)$. Early pachytene spermatocytes are characterized by complete pairing of the bivalents with synaptonemal complex formation except for some of the secondary constrictions, a distinct chromosome bouquet and moderate condensation of the chromatin and the centromeric hetecochromatin (Figures 1-4). The lateral components of the $\mathrm{X}$ and $\mathrm{Y}$ chromosomes can be fully reconstructed. Mid and late pachy- tene spermatocytes are characterized by a completed synaptonemal complex at the secondary constrictions, lack of a chromosome bouquet and increased condensation of the chromatin and centromeric heterochromatin (Figures 5-7). The lateral components of the $\mathrm{X}$ and $\mathrm{Y}$ chromosomes are tortuous, appear discontinuous and can not be fully reconstructed.

\section{RESULTS}

\subsection{Light microscopy}

Quantification of the seminiferous epithelium revealed an abnormally low level of the meiotic and later stages of the spermatogenesis as compared to normal testes (19). All types of germ cells were present in the tubules. The histology of the testicular tissue was otherwise normal. 
J. G. BerThelsen et al.: Meiotic chromosomes and steroid hormones
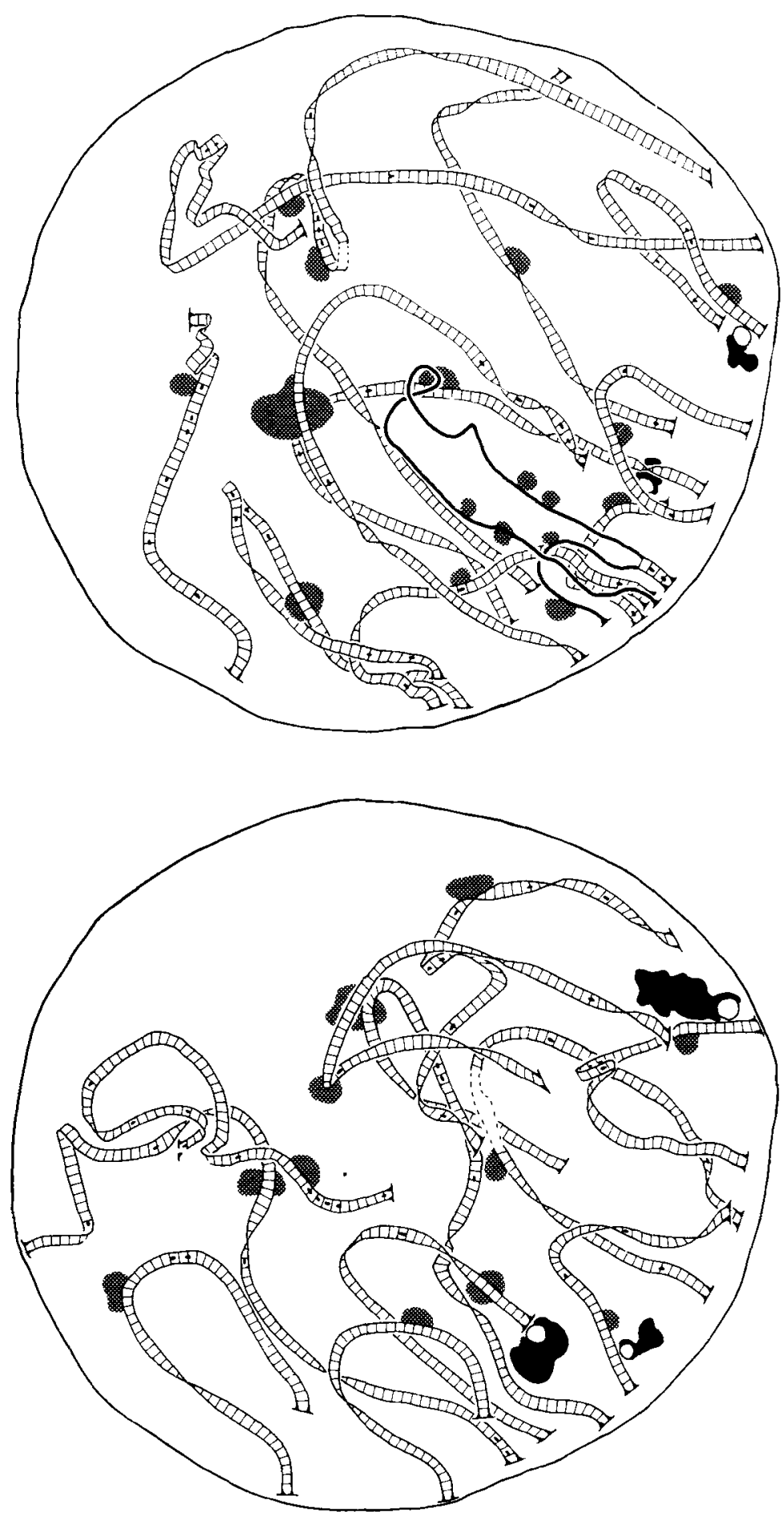

Figure 9. Complete reconstruction of an early pachytene spermatocyte (nucleus no. 1).

Mark the chromosome bouquet and the normal configuration of the XY bivalent. Symbols are explained in the legend to Figures 10-12. 
Table II

Stage, total autosomal complex length, number of recombination nodules of the 22 autosomal bivalents, number of autosomal bivalents without recombination nodules and synaptonemal complex length per recombination nodule in 7 early 2 mid and 1 late pachytene spermatocytes.

\begin{tabular}{|c|c|c|c|c|c|}
\hline & Nucleus & $\begin{array}{l}\text { Total autosomal } \\
\text { length }(\mu \mathrm{m})\end{array}$ & $\begin{array}{l}\text { Number of } \\
\text { recombination } \\
\text { nodules }\end{array}$ & $\begin{array}{c}\text { Number of auto- } \\
\text { somal bivalents } \\
\text { without nodules }\end{array}$ & $\begin{array}{l}\text { Synaptonemal complex } \\
\text { length per nodule }(\mu \mathrm{m})\end{array}$ \\
\hline \multirow{10}{*}{ 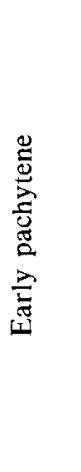 } & 1 & 233 & 89 & 1 & 2.6 \\
\hline & 5 & 224 & 54 & 1 & 4.2 \\
\hline & 6 & 260 & 76 & 1 & 3.4 \\
\hline & 7 & 235 & 87 & 0 & 2.7 \\
\hline & 8 & 255 & 58 & 1 & 4.4 \\
\hline & 9 & 240 & 66 & 0 & 3.6 \\
\hline & 10 & 218 & 85 & 2 & 2.6 \\
\hline & Mean & 238 & 74 & 0.9 & 3.4 \\
\hline & Reference mean (15) & 207 & 75 & 0.9 & 3.0 \\
\hline & $\begin{array}{l}\text { Statistical signi- } \\
\text { ficant difference }\end{array}$ & $\mathrm{p}<0.01$ & n.d. & n.d. & n.d. \\
\hline \multirow{5}{*}{ 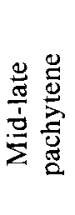 } & 2 & 261 & 13 & 8 & 20.0 \\
\hline & 3 & 286 & 14 & 6 & 20.4 \\
\hline & 4 & 271 & 19 & 3 & 15.0 \\
\hline & Mean & 273 & 15 & 5.7 & 18.5 \\
\hline & Reference mean (15) & 231 & $5-10$ & - & - \\
\hline
\end{tabular}

* Mann-Whitney ranksum test, n.d.: no difference.

\subsection{Electron microscopy}

\subsubsection{General morphology}

The ultrastructure of the synaptonemal complex, telomeres, centromeric heterochromatin, diffuse heterochromatin, knobs, nucleoli and recombination nodules was found to be indistinguisable from that reported for untreated spermatocytes $(8,15)$.

In addition to the morphological features of human spermatocyte nuclei described in the literature electron dense structures bridging the central region of the synaptonemal complex and thus uniting the two lateral components were observed in all pachytene nuclei (Figure 8). At mid and late pachytene the diameter, structure and electron density of these bridge-like structures resembled that of lateral components while they appeared less electron dense at early pachytene. In cross and oblique sections of the synaptonemal complex it was not always pos- sible to make an unambiguous distinction between the bridge-like structures and the recombination nodules. Each of the pachytene spermatocytes contained between 10 and 25 of the bridge-like structures, but they were most readily identified in the very late pachytene nucleus (no. 4) which represented a later pachytene stage than those investigated by HoLM \& RASMUSSEN (8).

\subsubsection{Autosomal bivalents}

The data concerning the 440 autosomal chromosomes are given in Tables II, III and IV. All nuclei contained 22 autosomal bivalents. With one exception (Figure 10) the two lateral components of all autosomal bivalents were completely aligned with a continuous or almost continuous synaptonemal complex extending between the telomeres of the bivalents. As in 


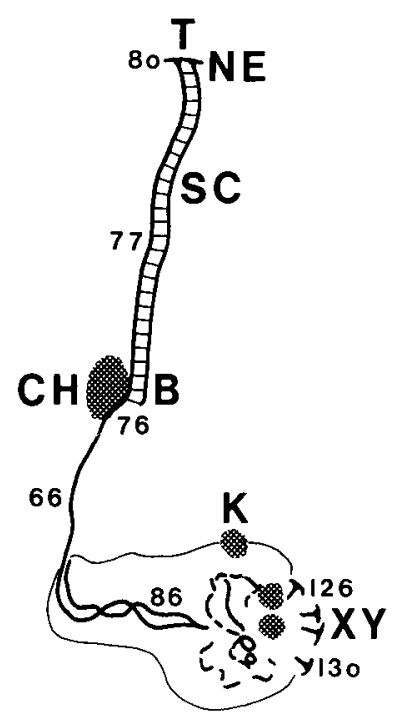

Figure 10. Reconstruction of a C-group bivalent with deletion of the entire long arm of the homolgue (nucleus no. 4).

It was not possible to identify the lateral component of the missing long arm elsewhere in the nucleus. The univalent long arm was intertwined with the lateral component of the $\mathrm{X}$ or $\mathrm{Y}$ chromosome without synaptonemal complex formation. This type of structural aberration is also encountered in untreated spermatocytes (15). B: Break point of the lateral component. $\mathrm{CH}$ : Centromeric heterochromatin, K: Knob on X or $\mathrm{Y}$ chromosome, NE: Nuclear envelope, SC: Synaptonemal complex. T: Telomeres, $\mathrm{XY}$ : Telomeres of the $\mathrm{X}$ and $\mathrm{Y}$ chromosomes, 66130: Section numbers.

\section{Table III}

Relative length and centromere index of the autosomal bivalents of 7 early, 2 mid and 1 late pachytene spermatocytes.

\begin{tabular}{|c|c|c|c|c|}
\hline \multirow[b]{2}{*}{ Bivalent } & \multicolumn{2}{|c|}{ Relative length* } & \multicolumn{2}{|c|}{ Centromere index } \\
\hline & $\begin{array}{l}\text { Present material } \\
\text { Mean (s.d.) }\end{array}$ & $\begin{array}{l}\text { Reference (15) } \\
\text { Mean (s.d.) }\end{array}$ & $\begin{array}{l}\text { Present material } \\
\text { Mean (s.d.) }\end{array}$ & $\begin{array}{l}\text { Reference (15) } \\
\text { Mean (s.d.) }\end{array}$ \\
\hline 1 & $9.0(0.1)$ & $8.4(0.4) \S$ & $49(4)$ & $51(4)$ \\
\hline 2 & $7.8(0.4)$ & $7.9(0.3)$ & $40(3)$ & $40(3)$ \\
\hline 3 & $6.4(0.3)$ & $6.6(0.4)$ & $47(2)$ & $47(2)$ \\
\hline 4 & $5.9(0.3)$ & $5.9(0.4)$ & $31(3)$ & $36(5) \S$ \\
\hline 5 & $5.9(0.3)$ & $5.9(0.3)$ & $26(2)$ & $29(4) \S$ \\
\hline 6 & $5.7(0.3)$ & $5.4(0.3)$ & $43(4)$ & $37(5) \S$ \\
\hline 7 & $5.5(0.5)$ & $5.3(0.3)$ & $35(5)$ & $38(6)$ \\
\hline 8 & $4.7(0.1)$ & $4.8(0.2)$ & $34(4)$ & $35(4)$ \\
\hline 9 & $4.9(0.3)$ & $5.0(0.4)$ & $35(5)$ & $37(6)$ \\
\hline 10 & $4.9(0.2)$ & $4.9(0.2)$ & $37(5)$ & $36(4)$ \\
\hline 11 & $4.4(0.2)$ & $4.5(0.3)$ & $34(4)$ & $36(6)$ \\
\hline 12 & $4.6(0.3)$ & $4.8(0.3)$ & $27(2)$ & $28(3)$ \\
\hline 13 & $3.7(0.2)$ & $3.8(0.3)$ & $10(3)$ & $12(5)$ \\
\hline 14 & $3.5(0.1)$ & $3.6(0.2)$ & $11(2)$ & $13(3) \S$ \\
\hline 15 & $3.3(0.2)$ & $3.3(0.2)$ & $10(4)$ & $11(2)$ \\
\hline 16 & $3.8(0.2)$ & $3.6(0.3)$ & $43(4)$ & $44(4)$ \\
\hline 17 & $3.6(0.4)$ & $3.8(0.3)$ & $33(3)$ & $33(3)$ \\
\hline 18 & $2.6(0.4)$ & $2.6(0.2)$ & $28(3)$ & $27(5)$ \\
\hline 19 & $2.6(0.5)$ & $2.7(0.3)$ & $41(3)$ & $42(4)$ \\
\hline 20 & $3.4(0.3)$ & $3.4(0.3)$ & $47(3)$ & $43(4)$ \\
\hline 21 & $1.6(0.1)$ & $1.7(0.1) \S$ & $21(5)$ & $23(6)$ \\
\hline 22 & $2.2(0.3)$ & $2.1(0.2)$ & $16(3)$ & $21(7)$ \\
\hline
\end{tabular}

\footnotetext{
* Percent of total autosomal synaptonemal complex length, $\S p<0.05$, Mann-Whitney ranksum test.
} 
Table IV

Various characteristics of the autosomal bivalents in 7 early, 2 mid and 1 late pachytene spermatocytes.

\begin{tabular}{|c|c|c|c|c|c|c|c|c|c|c|}
\hline \multirow{2}{*}{ Nucleus } & \multicolumn{7}{|c|}{ Early pachytene } & \multicolumn{3}{|c|}{ Mid and late pachytene } \\
\hline & 1 & 5 & 6 & 7 & 8 & 9 & 10 & 2 & 3 & 4 \\
\hline $\begin{array}{l}\text { Synaptonemal complex } \\
\text { lacking in the } \\
\text { secondary constriction* }\end{array}$ & $1,9,16$ & 1,9 & 1,9 & 1,9 & 1,9 & $1,9,16$ & 1 & & & \\
\hline $\begin{array}{l}\text { Secondary constriction } \\
\text { with diffuse } \\
\text { heterochromatin* }\end{array}$ & & & & & & & & 1,9 & $1,9,16$ & $1,9,16$ \\
\hline $\begin{array}{l}\text { Chromosomes with } \\
\text { nucleolus and nucleo- } \\
\text { lus organizer region* }\end{array}$ & $\begin{array}{l}13-15 \\
21,22\end{array}$ & $\begin{array}{l}13-15 \\
21,22\end{array}$ & $\begin{array}{l}13-15 \\
21,22\end{array}$ & $\begin{array}{l}13-15 \\
21,22\end{array}$ & $\begin{array}{l}13-15 \\
21,22\end{array}$ & $\begin{array}{l}13-15 \\
21,22\end{array}$ & $\begin{array}{l}13-15 \\
21,22\end{array}$ & 15 & 13,14 & $\begin{array}{l}14,15 \\
21\end{array}$ \\
\hline $\begin{array}{l}\text { Free nucleoli } \\
\text { (diameter greater } \\
\text { than } 1 \mu \mathrm{m} \text { ) }\end{array}$ & 2 & 1 & 2 & 1 & 1 & 2 & 1 & - & 1 & - \\
\hline $\begin{array}{l}\text { Knobs* } \\
\text { (Figures in parenthesis } \\
\text { are the number of } \\
\text { knobs per bivalent) }\end{array}$ & & & & & & & & $\begin{array}{l}5(3) \\
6(1) \\
8(2) \\
11(1) \\
12(2) \\
16(1)\end{array}$ & $\begin{array}{l}4(1) \\
8(4)\end{array}$ & $\begin{array}{l}1(1) \\
2(2) \\
6(2) \\
9(2) \\
11(1) \\
12(2) \\
14(1) \\
17(1)\end{array}$ \\
\hline $\begin{array}{l}\text { Bivalents without } \\
\text { recombination nodules* }\end{array}$ & 18 & 21 & 4 & - & 22 & - & 15.22 & $\begin{array}{l}3,11 \\
12,13 \\
19,20 \\
21,22\end{array}$ & $\begin{array}{l}6,8 \\
14,15 \\
17,19\end{array}$ & $\begin{array}{l}18,21 \\
22\end{array}$ \\
\hline
\end{tabular}

\footnotetext{
* Figures are chromosome numbers.
}

untreated spermatocytes the synaptonemal complex was not fully organized in some of the secondary constrictions in the 7 early pachytene nuclei (Table IV). In the $2 \mathrm{mid}$ and 1 late pachytene nuclei synaptonemal complex formation was complete also in these regions and with one exception the diffuse heterochromatin of the secondary constrictions could be identified (Table IV).

Most of the acrocentric chromosomes possessed a major nucleolus with a nucleolus organizer region. In addition $0-2$ free major nucleoli were present in the nucleoplasm (Table IV).

A semicondensed globular structure on one of the two longer $\mathrm{C}$ group chromosomes was identified in each of the nuclei (Figure 7). As chromosomes 6 and 7 cannot be distinguished unequivocally by length and centromere index, it is still uncertain which of the two chromosomes carries the marker structure.

\subsubsection{XY bivalents}

The data concerning the $X Y$ bivalents are given in Table V. In the 7 early pachytene spermatocytes the XY hivalents were completely reconstructed, while at mid and late pachytene complete reconstruction was impossible due to 
Table V

Relative length, centromere index, number of knobs, synaptonemal complex length and number of recombination nodules of the $X$ and $Y$ chromosomes in 7 early, 2 mid and 1 late pachytene spermatocytes.

\begin{tabular}{|c|c|c|c|c|c|c|c|}
\hline & Nucleus & $\begin{array}{l}\text { Lateral com- } \\
\text { ponent relative } \\
\text { length of } \mathrm{X}^{*}\end{array}$ & $\begin{array}{l}\text { Lateral com- } \\
\text { ponent relative } \\
\text { length of } \mathrm{Y}^{*}\end{array}$ & $\begin{array}{l}\text { Centromere } \\
\text { index of } Y\end{array}$ & $\begin{array}{l}\text { Number of } \\
\text { knobs X (Y) }\end{array}$ & $\begin{array}{l}\text { Synaptonemal } \\
\text { complex rela- } \\
\text { tive length* }\end{array}$ & $\begin{array}{l}\text { Number of } \\
\text { recombination } \\
\text { nodules }\end{array}$ \\
\hline \multirow{10}{*}{ 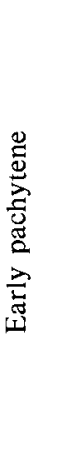 } & 1 & 6.3 & 1.8 & 49 & $4(1)$ & 0.2 & 2 \\
\hline & 5 & 4.1 & 1.5 & 35 & $1(1)$ & 0.0 & - \\
\hline & 6 & 4.2 & 1.3 & 34 & $2(1)$ & 0.4 & 0 \\
\hline & 7 & 4.5 & 1.6 & 47 & $1(1)$ & 0.4 & 1 \\
\hline & 8 & 4.7 & 1.6 & 49 & $3(1)$ & 0.4 & 1 \\
\hline & 9 & 5.5 & 1.8 & 32 & $6(1)$ & 0.4 & 0 \\
\hline & 10 & 7.6 & 2.0 & 50 & $6(1)$ & 0.5 & 1 \\
\hline & Mean & 5.3 & 1.7 & 42 & $3(1)$ & 0.3 & 0.7 \\
\hline & Reference mean $(8,15)$ & 5.1 & 1.7 & & & 0.4 & 0.9 \\
\hline & $\begin{array}{l}\text { Statistical signi- } \\
\text { ficant difference }{ }^{* *}\end{array}$ & n.d. & n.d. & & & n.d. & n.d. \\
\hline \multirow{5}{*}{ 善 } & 2 & - & - & - & - & 0.3 & 0 \\
\hline & 3 & - & - & - & - & 0.0 & - \\
\hline & 4 & - & - & - & - & 0.0 & - \\
\hline & Mean & - & - & - & - & 0.1 & 0 \\
\hline & Reference mean $(8,15)$ & - & - & - & - & 0.1 & 0 \\
\hline
\end{tabular}

* Percent of total autosomal synaptonemal complex length, ** Mann-Whitney ranksum test, n.d.: no difference.

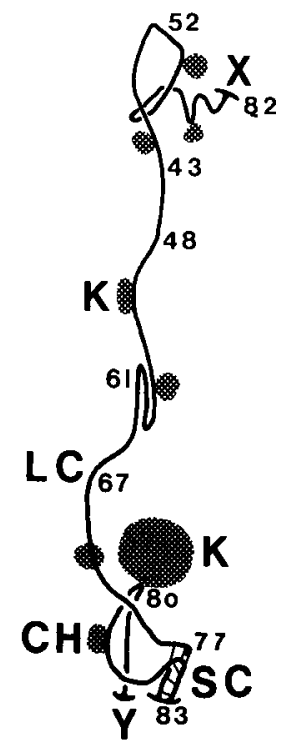

Figure 11. Reconstruction of the $\mathrm{X}$ and $\mathrm{Y}$ chromosomes from an early pachytene spermatocyte (nucleus no. 10$)$.

$\mathrm{CH}$ : Centromeric heterochromatin of the $\mathrm{Y}$ chromosome, K: Knob, LC: Lateral component, SC: Synaptonemal complex of the homologous region, $\mathrm{X}$ : Telomere of the differential segment of the $X$ chromosome, Y: Telomere of the differential segment of the $\mathrm{Y}$ chromosome, 43-83: Section numbers. 


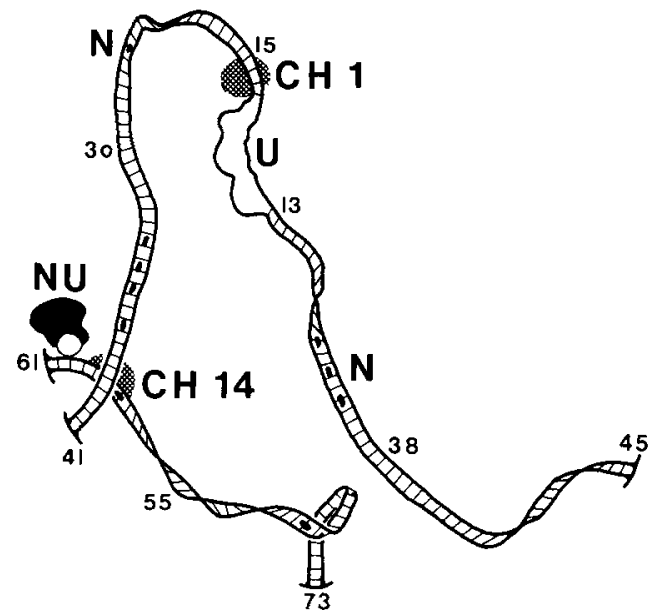

Figure 12. Reconstruction of chromosomes no. I and 14 from an early pachytene spermatocyte (nucleus no. 10$)$.

$\mathrm{CH}$ : Centromeric heterochromatin, $\mathrm{N}$ : Recombination nodule, NU: Nucleolus with nucleolus organizer region, U: Lateral components of the unpaired region of the secondary constriction. 13-73: Section numbers.

Figure 13. Distribution of nodule-nodule distances in 7 early pachytene spermatocytes.

The columns represent the actual frequency of distances in the various classes. Each class equals 0.1 $\mu \mathrm{m}$. Range of distances: $0.12-7.23 \mu \mathrm{m}, 3.1 \%$ of the distances are larger than $5.0 \mu \mathrm{m}$. The dots represent the expected frequency of distances in the various classes assuming random distribution of the recombination nodules along the synaptonemal complex. $3.9 \%$ of these distances are larger than $5.0 \mu \mathrm{m}$.

Figure 14. Distribution of telomere-nodule distances in 7 early pachytene spermatocytes.

For explanation of symbols see Figure 13. Range of actual distances: $0.06-6.24 \mu \mathrm{m}, 4.5 \%$ of the distances are larger than $5.0 \mu \mathrm{m}$. Assuming random distribution $7.5 \%$ of the distances are expected to be larger than $5.0 \mu \mathrm{m}$.

Figure 15. Distribution of centromere-nodule distances in 7 early pachytene spermatocytes.

For explanation of symbols see Figure 13. Range of actual distances: $0.09-11.50 \mu \mathrm{m}, 9.3 \%$ of the distances are larger than $5.0 \mu \mathrm{m}$. Assuming random distribution $7.5 \%$ of the distances are expected to be larger than $5.0 \mu \mathrm{m}$.

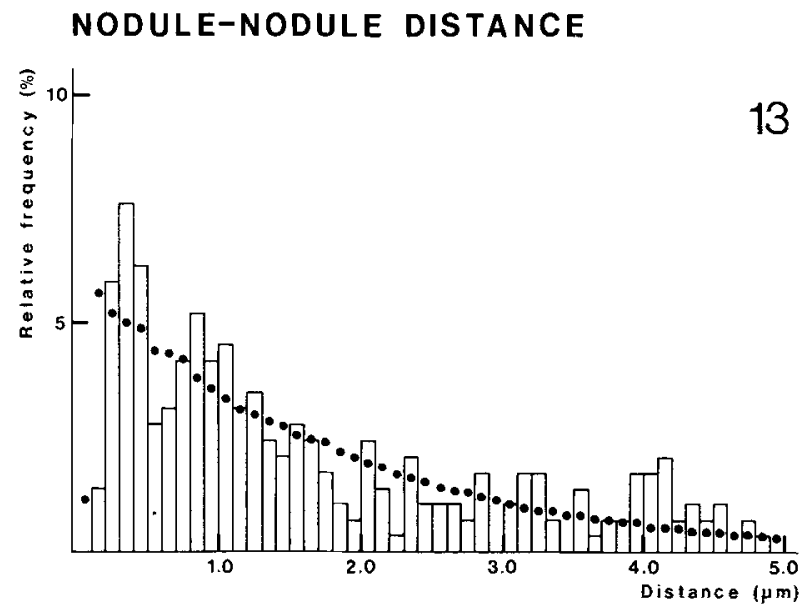

TELOMERE-NODULE DISTANCE

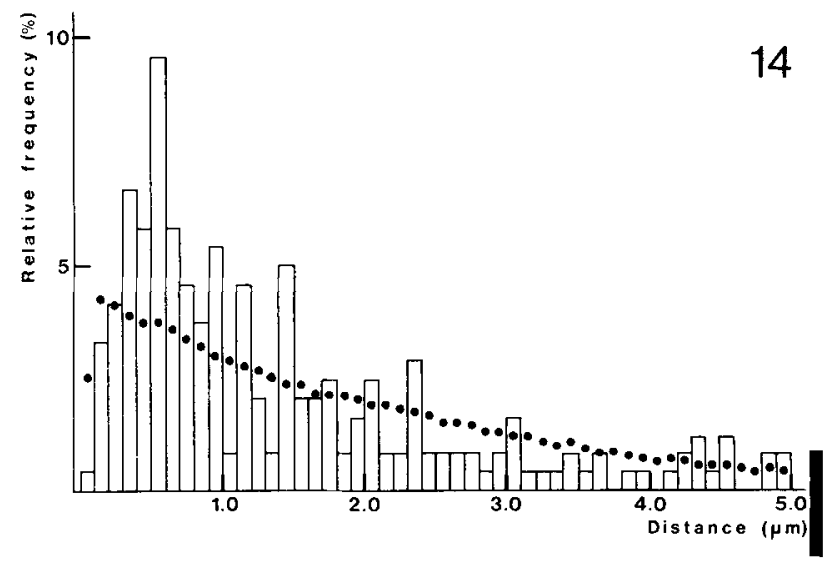

CENTROMERE-NODULE DISTANCE

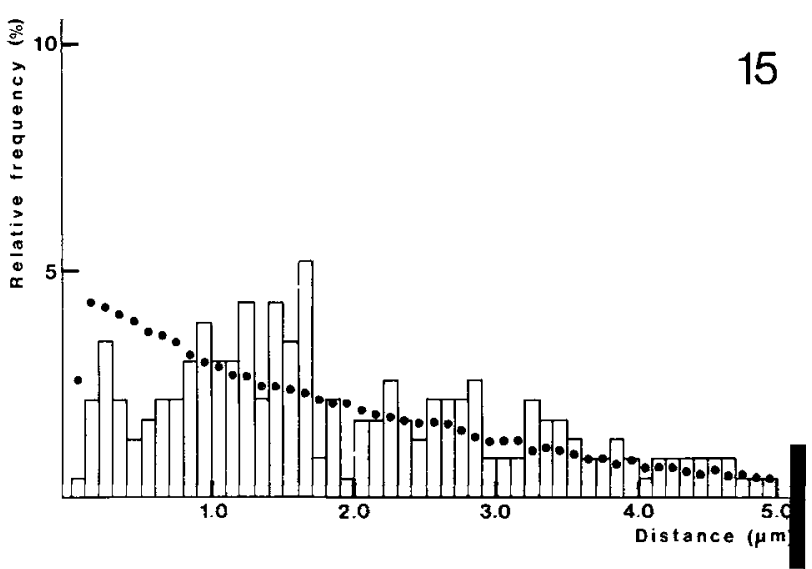


Table VI

Recombination nodules and synaptonemal complex relative length per nodule in 7 early pachytene spermatocytes.

\begin{tabular}{|c|c|c|c|c|}
\hline \multirow{2}{*}{ Bivalent } & \multicolumn{2}{|c|}{ Number of recombination nodules } & \multicolumn{2}{|c|}{$\begin{array}{l}\text { Synaptonemal complex relative length } \\
\text { per nodule }\end{array}$} \\
\hline & $\begin{array}{l}\text { Present material } \\
\text { Mean (Range) }\end{array}$ & $\begin{array}{l}\text { Reference (15) } \\
\text { Mean (Range) }\end{array}$ & $\begin{array}{l}\text { Present material } \\
\text { Mean }\end{array}$ & $\begin{array}{c}\text { Reference (15) } \\
\text { Mean }\end{array}$ \\
\hline 1 & $5.9(3-8)$ & $7.2(2-13)$ & 1.5 & 1.2 \\
\hline 2 & $7.7(4-11)$ & $6.0(2-10)$ & 1.0 & 1.3 \\
\hline 3 & $4.3(1-7)$ & $4.4(2-10)$ & 1.5 & 1.5 \\
\hline 4 & $4.3(0-12)$ & $3.4(0-6)$ & 1.4 & 1.7 \\
\hline 5 & $6.1(3-11)$ & $4.2(0-7)$ & 1.0 & 1.4 \\
\hline 6 & $4.0(1-6)$ & $4.6(1-11)$ & 1.4 & 1.2 \\
\hline 7 & $3.3(1-7)$ & $4.5(0-10)$ & 1.7 & 1.2 \\
\hline 8 & $3.3(1-5)$ & $3.2(1-7)$ & 1.4 & 1.5 \\
\hline 9 & $4.3(3-7)$ & $3.2(1-7)$ & 1.1 & 1.6 \\
\hline 10 & $4.6(2-8)$ & $3.6(3-8)$ & 1.1 & 1.4 \\
\hline 11 & $3.1(2-6)$ & $3.2(1-7)$ & 1.5 & 1.4 \\
\hline 12 & $2.9(1-7)$ & $3.4(1-10)$ & 1.6 & 1.4 \\
\hline 13 & $2.6(2-3)$ & $2.9(0-8)$ & 1.4 & 1.3 \\
\hline 14 & $2.0(1-3)$ & $2.2(0-5)$ & 1.8 & 1.6 \\
\hline 15 & $2.0(0-6)$ & $2.6(0-7)$ & 1.7 & 1.3 \\
\hline 16 & $2.1(1-4)$ & $2.6(1-6)$ & 1.8 & 1.4 \\
\hline 17 & $2.3(1-4)$ & $2.8(1-7)$ & 1.6 & 1.4 \\
\hline 18 & $1.4(0-3)$ & $2.2(0-5)$ & 1.8 & 1.2 \\
\hline 19 & $2.3(1-3)$ & $2.0(1-5)$ & 1.1 & 1.4 \\
\hline 20 & $2.3(1-4)$ & $2.5(0-5)$ & 1.5 & 1.4 \\
\hline 21 & $2.0(0-4)$ & $1.0(0-2)$ & 0.8 & $1.7 \S$ \\
\hline 22 & $1.0(0-4)$ & $1.6(0-4)$ & 2.2 & 1.3 \\
\hline Mean & 3.4 & 3.3 & 1.4 & 1.4 \\
\hline
\end{tabular}

* Percent of total autosomal synaptonemal complex length, $\S p<0.05$. Mann-Whitney ranksum test.

envelope some distance away from the remaining three telomeres. This is unusual, but is thought to be a variety of the normal rather than an anomaly (Figure 11).

\subsubsection{Recombination nodules}

The data concerning the recombination nodules are given in Tables II, IV, V and VI.

In the early pachytene spermatocytes the distances between neighbour nodules, between telomeres and the nearest nodule and between centromeres and the nearest nodule were analysed (Figures 13-15). The values were compared to the theoretical distributions of these distances assuming random distribution of the nodules along the chromosomes. For details of this procedure see Rasmussen \& Holm (15). The comparison showed that nodule-nodule distances below $0.3 \mu \mathrm{m}$ were less frequent than expected, while telomere-nodule distances below $1.5 \mu \mathrm{m}$ were more frequent than expected. The centromere-nodule distances below $0.9 \mu \mathrm{m}$ were less frequent than expected from a random distribution. These findings are very similar to the results from untreated spermatocytes (15).

In the early pachytene spermatocytes $4 \%$ (95\% confidence limits: $1.4-8.2 \%$ ) of the autosomal bivalents were devoid of recombination nodules, as compared to $3 \%$ in normal untreated spermatocytes (no statistical significant difference, $\mathrm{Chi}^{2}$ test). The expected number 
assuming random distribution of recombination nodules on the synaptonemal complexes is $7 \%$.

This difference is not statistically significant (Chi ${ }^{2}$ test).

\section{DISCUSSION}

The present study did not reveal significant effects on the ultrastructure of pachytene spermatocytes of the treatment with steroid hormones. Each nucleus had 46 chromosomes. Homologous chromosome pairing and changes in the morphological features of the nuclei during meiotic prophase followed the pattern described for untreated spermatocytes. The difference in mean total autosomal synaptonemal complex length (Table II) between the treated and untreated spermatocytes is probably an unspecific difference in the degree of contraction of the chromosomes. The slight differences in relative lengths and centromere indices (Table III) as compared to untreated spermatocytes are probably due to random variation. One structural aberration among a total of 454 chromosomes does not exceed the frequency found in untreated spermatocytes. In the early pachytene nuclei the number and distribution of recombination nodules were very similar to that reported for untreated spermatocytes. In the mid and late pachytene spermatocytes the number of recombination nodules had declined to the low levels found in untreated spermatocytes.

As reference for the present investigation serve almost 2000 completely reconstructed pachytene chromosomes from 5 normal men. This number and the number of chromosomes from the present investigation are sufficiently large for a qualitative and quantitative evaluation.

The bridge-like structures found in the synaptonemal complex are not peculiar to this patient, as they have been identified in zygotene and pachytene spermatocytes from other human males as well. The structures resemble the lateral component cross connections of the synaptonemal complex in rat reported by MoENs (12) although his theory of breakage and rearrangement of the lateral components during crossing over is not supported by the present investigation. The role of the bridge-like structures in meiosis and their possible relationship to the different types of recombination nodules is still uncertain.

As the classification of the individual chromosomes rests on the relative lengths and centromere indices, marker structures add to the accuracy of the identification. This is especially true for the C-group, where the differences between chromosomes are small. Accordingly the new marker knob will be useful in future classifications.

More investigations are needed to exclude adverse effects on chromosomal behaviour of the employed hormones, but the present three dimensional reconstruction of the synaptonemal complex in 460 pachytene chromosomes has not indicated any lasting adverse effect on the meiotic process or on the integrity of the chromosomes following treatment with cyproterone acetate, nor was any acute adverse effect revealed during treatment with d-norgestrel and testosterone enanthate except for a general depression of spermatogenesis during treatment.

\section{ACKNOWLEDGEMENTS}

We are grateful to Prof. D. voN Wettstein for his support and valuable criticism of the manuscript. S. W. Rasmussen and P. B. Holm have generously shared their technical knowledge of and facilities for the three dimensional reconstruction and allowed us liberal access to their original data. We are greatly indepted for their support in all phases of the work. JEAN SAGE has expertly performed the serial sectioning and cand. stat. L. SEJersen the calculations of random nodule distances. The work was supported by grant 202-76-1 BIO DK from the Commision of the European Communities and by the Danish Medical Research Council.

\section{REFERENCES}

1. ANDERson, P. J.: Purification and quantitation of glutaraldehyde and its effects on several enzyme activities in skeletal muscle. J. Histochem. Cytochem. 15, 652-661 (1967)

2. Carpenter, A. T. C.: Electron microscopy of meiosis in Drosophila melanogaster. II. The recombination nodule - a recombination associated structure at pachytene? Proc. Nat. Acad. Sci. 72. 3186-3189 (1975) 
3. Carpenter, A. T. C.: Recombination nodules and synaptonemal complex in recombinationdefective Drosophila melanogaster females. Chromosoma 75, 259-292 (1979)

4. Clermont, Y.: The cycle of the seminiferous epithelium in man. Amer. J. Anat. 112, 35-51 (1963)

5. Føgh, M., C. S. Corker, W. M. Hunter, H. Mclean, J. Philip, G. Schou \& N. E. SkakkeBÆK: The effect of low doses of cyproterone acetate on some functions of the reproductive system in normal men. Acta Endocrinol. 91, 545-552 (1979)

6. Føgh, M., C. S. Corker, H. McLean, W. M. Hunter, J. B. Petersen, J. Philip, G. Schou \& N. E. SкаккевеK: Regulation of male fertility with a combination of $d$-norgestrel and testosterone enanthate: A clinical trial. Acta Endocrinol. In press (1980)

7. Hanson, V., M. Ritzén, K. Purvis \& F. S. FRENCH (eds.): Endocrine approach to male contraception. Int. J. Androl. Suppl. 2. (1978)

8. Holm, P. B. \& S. W. Rasmussen: Human meiosis I. The human pachytene karyotype analyzed by three dimensional reconstruction of the synaptonemal complex. Carlsberg Res. Commun 42, 283-323 (1977)

9. Holm, P. B. \& S. W. Rasmussen: Human meiosis III. Electron microscopical analysis of chromosome pairing in an individual with a balanced translocation $46, \mathrm{XY}, \mathrm{t}(5 \mathrm{p}-; 22 \mathrm{p}+)$. Carlsberg Res. Commun. 43, 320-350 (1978)

10. Holm, P. B., S. W. Rasmussen \& D. von WetTSTEIN: The possible contribution of electron microscopy to the understanding of the mechanism of non-disjunction in man. Mutation Research 61, 115-119 (1979)

11. Hultén, M.: Chiasma distribution at diakinesis in the normal human male. Hereditas $76,55-78$ (1974)

12. Moens, P. B.: Lateral element cross connections of the synaptonemal complex and their relationship to chiasmata in rat spermatocytes. Canad. J. Genet. Cytol. 20, 567-579 (1978)

13. Patanel.i, D. J. (ed.): Hormonal control of male fertility. DHEW Publication No (NIH) 78-1097 (1977)

14. Paris Conference 1971: Standardization in human cytogenetics. Cytogenetics 11, 313-362 (1972)

15. Rasmussen, S. W. \& P. B. Holm: Human meiosis II. Chromosome pairing and recombination nodules in human spermatocytes. Carlsherg Res. Commun. 43, 275-327 (1978)

16. Rasmussen, S. W. \& P. B. Holm: Human meiosis IV. The elimination of synaptonemal complex fragments from metaphase I bivalents of human spermatocytes. Carlsberg Res. Commun. 43, 423-438 (1978)

17. Roosen-RUnGe, E. C.: The process of spermatogenesis in mammals. Biol. Rev. 33, 343-377 (1962)

18. SкакKebeK, N. E.: Quantification of the seminiferous epithelium in the human testis. With special reference to fertility and chromosome complement. Thesis, FADL, Copenhagen (1974)

19. Skakкebak, N. E. \& C. G. Heller: Quantification of human seminiferous epithelium. J. Reprod. Fert. 32, 379-389 (1973)

20. Solari, A. J. \& L. L. Tres: The threedimensional reconstruction of the XY chromosomal pair in human spermatocytes. J. Cell. Biol. $45,43-53(1970)$

21. Westergaard, M. \& D. von Wettstein: The synaptinemal complex. Ann. Rev. Genet. 6, 71$110(1972)$ 